\title{
QUALIDADE FISIOLÓGICA E RESISTÊNCIA DO RECOBRIMENTO DE SEMENTES DE MILHO ${ }^{1}$
}

\author{
PATRÍCIA MARLUCI DA CONCEIÇÃO², HENRIQUE DUARTE VIEIRA ${ }^{3}$
}

\begin{abstract}
RESUMO - Este trabalho foi desenvolvido com o objetivo de avaliar a qualidade fisiológica de sementes de milho UENF 506-8 recobertas e a resistência do recobrimento utilizando diferentes proporções de cimentante. Foi utilizada no recobrimento das sementes uma mistura de calcário e meio de cultura. Como cimentante foi utilizada cola a base de acetato de polivinila (PVA). O recobrimento das sementes de milho foi realizado com uma mistura de $70 \%(\mathrm{p} / \mathrm{p})$ de calcário, $10 \%(\mathrm{p} / \mathrm{p})$ de meio de cultura semi-sólido JNFb e $20 \%(\mathrm{p} / \mathrm{p})$ de água. Foram adicionadas a essa mistura diferentes proporções de cimentante: 0,$5 ; 1 ; 2 ; 3 ; 4$ e $5 \%(\mathrm{p} / \mathrm{p})$. Para avaliação da resistência do recobrimento foi simulado o transporte e a semeadura manual, e a semeadura mecânica das sementes recobertas. A avaliação da qualidade fisiológica das sementes foi realizada em sementes nuas (controle) e sementes recobertas com as proporções de cimentante: 0,$5 ; 1 ; 2 ; 3 ; 4$ e $5 \%$. O aumento da proporção de cimentante de 2 para 3\% causou uma pequena redução na velocidade da germinação, na velocidade de emergência e na emergência, mas não afetou o número final de plântulas normais no teste de germinação e teste frio. Para a semeadura manual recomenda-se a utilização de $2 \%$ de cimentante e para a semeadura mecanizada $4 \%$ de cimentante.
\end{abstract}

Termos para indexação: recobrimento, cimentante, germinação, vigor.

\section{PHYSIOLOGIC QUALITY AND RESISTANCE OF THE COVERING OF CORN SEEDS}

\begin{abstract}
This work was developed with the objective of evaluating the physiologic quality of corn seeds UENF 506-8 covered and the resistance of the covering using different proportions of cement. It was used in the covering of the seeds a mixture of lime and culture media. As cement was used polivinil acetate glue (PVA). The covering of the corn seeds was executed with a mixture of $70 \%(\mathrm{w} / \mathrm{w})$ of lime, $10 \%(\mathrm{w} / \mathrm{w})$ of semi-solid culture media $\mathrm{JNFb}$ and $20 \%(\mathrm{w} / \mathrm{w})$ of water. In the mixture different proportions were added: 0,$5 ; 1 ; 2 ; 3 ; 4$ and $5 \%(\mathrm{w} / \mathrm{w})$. Evaluating the resistance of the covering was simulated the transport and the manual seeding, and the mechanical seeding of the covered seeds. The evaluation of the physiologic quality of the seeds was accomplished in seeds not covered and covered seeds with the proportions of cement: 0,$5 ; 1 ; 2 ; 3 ; 4$ and $5 \%$. The increase of the proportion of cement of 2 for $3 \%$ caused a small reduction no significant in the speed of the germination, emergency speed and emergency, but it didn't affect the final number of normal plants in the germination test and cold test. For the manual seeding the use of $2 \%$ of cement is recommended and for the mechanical seeding $4 \%$ of cement.
\end{abstract}

INDEX TERMS: cement, germination, vigor

\begin{abstract}
${ }^{1}$ Submetido em 14/03/2007. Aceito para publicação em 03/02/2008. Parte da Dissertação de Mestrado do primeiro autor apresentada à Universidade Estadual do Norte Fluminense Darcy Ribeiro (UENF).
\end{abstract}

${ }^{2}$ Eng. Agr ${ }^{\circ}$, mestranda em Produção Vegetal, UENF, email: patymarluci@yahoo.com.br

${ }^{3}$ Eng. Agr ${ }^{\circ}$, Dr., Professor Associado, Produção Vegetal, UENF, Av.: Alberto Lamego, 2000, Parque Califórnia, Campos dos Goytacazes, CEP 28013-602,email:henrique@uend.br 


\section{INTRODUÇÃO}

O recobrimento de sementes é uma técnica usada há bastante tempo, principalmente em hortaliças, florestais e ornamentais. Consiste num mecanismo de aplicação de materiais inertes e adesivos, objetivando aumentar o tamanho da semente, bem como alterar sua forma e textura para facilitar a semeadura direta. Além disso, apresenta a vantagem de possibilitar a utilização conjunta de nutrientes, fungicidas, inseticidas, herbicidas e microrganismos benéficos (Nascimento et al., 1993).

No Brasil, para as grandes culturas, o recobrimento de sementes ainda é considerado uma nova tecnologia, pois faltam muitas informações técnico-científicas (Bays et al., 2007). A agregação de valor às sementes, utilizando métodos e tecnologias de produção como o recobrimento de sementes, é uma exigência de um mercado cada vez mais competitivo (Medeiros et al., 2004).

O recobrimento de sementes pode viabilizar a inoculação de inúmeros microrganismos que têm a capacidade de beneficiar a implantação e desenvolvimento dos cultivos. Para a inoculação do rizóbio até o momento da simbiose, o material de inoculação que tem demonstrado ser o mais apropriado é a turfa. Para a proteção do inoculante, as sementes de diferentes culturas podem ser recobertas com materiais como fosfatos de rocha e carbonato de cálcio (Giménez-Sampaio e Sampaio, 1994). Meios de cultura líquidos ou semi-sólidos também podem ser utilizados como inoculantes de bactérias, onde o recobrimento será utilizado para aderir o meio de cultura à semente, além de contribuir para um micro-ambiente favorável à sobrevivência da bactéria.

No recobrimento de sementes utiliza-se basicamente um material de enchimento seco, de granulometria fina, e um cimentante que deve ser um adesivo não fitotóxico e solúvel em água. Segundo Mendonça (2003), para evitar a desintegração da camada do recobrimento durante o processo de transporte, manuseio ou semeadura, são utilizados materiais cimentantes (adesivos) que devem ter afinidades com os demais ingredientes e elevado poder fixação, no sentido de se utilizar a menor proporção de cimentante no recobrimento.

A definição da proporção de cimentante implica no dilema entre a necessidade de se ter resistência física, e a limitação do uso de cimentantes, sendo então necessário avaliar a resistência do recobrimento, para que se possa utilizar a menor proporção possível de cimentantes, sem afetar a qualidade final do produto (Silva e Nakagawa, 1998a).

Apesar das vantagens do recobrimento, alguns autores afirmam que este processo pode afetar a qualidade fisiológica das sementes. Neste sentido, Franzin et al (2004), verificaram que a germinação de sementes de alface foi inibida após o recobrimento. Silva e Nakagawa (1998b) observaram retardamento da germinação das sementes recobertas por até 20 dias, segundo os mesmos autores, a superação do obstáculo imposto pelo recobrimento está intimamente relacionado ao vigor da semente e por isso, pequenas diferenças no vigor contribuem para a desuniformidade da população inicial de plantas. Contudo, vencida a barreira, as plântulas se igualam na velocidade de crescimento, formando mudas uniformes em massa fresca e seca, tanto em condições de laboratório quanto em viveiros de mudas.

Bays et al. (2007) observaram que o recobrimento de sementes de soja com polímero não afetou a qualidade fisiológica das sementes. Binneck et al. (1999), estudando o efeito do recobrimento das sementes sobre a germinação e a emergência de sementes de trevo-branco, concluíram que com o uso de sementes recobertas, podem-se conseguir populações com altas taxas de germinação e emergência de plântulas.

Visando utilizar o recobrimento de sementes como meio de inoculação de bactérias diazotróficas em sementes de milho, o presente trabalho teve como objetivo avaliar a qualidade fisiológica de sementes de milho recobertas e a resistência do recobrimento utilizando diferentes proporções de cimentante.

\section{MATERIAL E MÉTODOS}

Os experimentos foram realizados no Setor de Produção e Tecnologia de Sementes do Laboratório de Fitotecnia e em casa de vegetação, ambos pertencentes ao Centro de Ciências e Tecnologias Agropecuárias (CCTA) da Universidade Estadual do Norte Fluminense Darcy Ribeiro (UENF) em Campos dos Goytacazes - RJ. Foram utilizadas sementes de milho híbrido UENF 506-8.

O material de recobrimento utilizado foi o calcário dolomítico (granulometria fina) com adição de meio de cultura $\mathrm{JNFb}$ (meio de inoculação de bactérias diazotróficas). Como cimentante foi utilizada cola a base de acetato de polivinila (PVA) dissolvida em água. O recobrimento das sementes de milho foi realizado com a mistura de $70 \%(\mathrm{p} / \mathrm{p})$ de calcário, $10 \%(\mathrm{p} / \mathrm{p})$ de meio de cultura semi-sólido JNFb (Baldani et al., 1992) e 20\% (p/p) de água. Essa mistura foi realizada dentro de um béquer. Foram adicionadas a essa 
mistura diferentes proporções de cimentante: 0,$5 ; 1 ; 2 ; 3 ; 4$ e $5 \%(\mathrm{p} / \mathrm{p})$.

As sementes foram recobertas e postas a secar ao ar livre, durante um período de 24 horas, sobre um recipiente polvilhado com calcário a fim de evitar que as mesmas ficassem aderidas ao fundo do recipiente.

Para avaliação da resistência do recobrimento quatro repetições de 30 sementes recobertas de cada tratamento foram pesadas e armazenadas em sacos de papel multifoliado. Esses sacos foram colocados dentro de uma sacola plástica e, simulando o transporte das sementes, os sacos de papel foram agitados visando a colisão entre eles. Em seguida, os sacos de papel foram retirados da sacola e lançados, individualmente, de uma altura de 1 metro simulando os danos de uma semeadura manual ao recobrimento. Para a determinação do material de recobrimento perdido as sementes foram pesadas novamente.

Avaliando a resistência do recobrimento à semeadura mecânica, quatro repetições de 30 sementes recobertas, de cada tratamento, foram pesadas e submetidas à semeadora de plantio direto. As sementes após passarem pelo disco e o duto da semeadora foram coletadas e pesadas para determinação da porcentagem de material de recobrimento perdido.

A avaliação da qualidade fisiológica das sementes foi realizada com sementes nuas (controle) e sementes recobertas com as proporções de cimentante: 0,$5 ; 1 ; 2 ; 3 ; 4$ e $5 \%$ pelos testes de germinação (TG), primeira contagem do TG, teste frio sem solo, emergência de plantas em casa de vegetação e índice de velocidade de emergência (IVE).

$\mathrm{O}$ teste de germinação (TG) foi realizado de acordo com as recomendações contidas nas Regras para Análises de Sementes (Brasil, 1992) sendo utilizado quatro repetições de 25 sementes para cada tratamento.

A primeira contagem do TG foi realizada conforme metodologia prescrita para o $\mathrm{TG}$, sendo o resultado expresso pela porcentagem das plântulas normais avaliadas no quarto dia após o início do teste.

Para execução do teste de frio sem solo, quatro repetições de 25 sementes de cada tratamento, foram distribuídas em papel germiteste umedecido com uma quantidade de água equivalente a 2,5 vezes o peso do papel. Após a semeadura os rolos foram colocados no interior de sacos plásticos e estes foram mantidos em câmara regulada a $10^{\circ} \mathrm{C}$, durante sete dias. Após esse período, os rolos no interior dos sacos plásticos foram transferidos para um germinador regulado à temperatura alternada de $20-30^{\circ} \mathrm{C}$, onde permaneceram por mais sete dias. A avaliação da germinação foi realizada de acordo com as recomendações contidas nas Regras para
Análise de Sementes (Brasil, 1992).

Para a avaliação da emergência de plantas em casa de vegetação foram utilizadas quatro repetições de 10 sementes. Os diferentes tratamentos foram semeados em vasos plásticos de cinco litros preenchidos com areia de textura média. Estes foram colocados em casa de vegetação e 15 dias após à semeadura foi realizada a avaliação do número de plântulas normais emergidas.

O IVE foi conduzido juntamente com a avaliação da emergência de plantas em casa de vegetação, contabilizandose diariamente as plântulas emergidas a partir das primeiras plântulas até o décimo quinto dia após a semeadura. Os índices foram calculados de acordo com a fórmula de Maguire (1962).

Os resultados foram submetidos à análise de variância (F a $5 \%$ de probabilidade). Os tratamentos da avaliação de resistência foram comparados via análise de regressão polinomial e pelo teste de Tukey a $5 \%$ de probabilidade. Os resultados das avaliações da qualidade fisiológica das sementes foram analisados pelo teste de Tukey a 5\% de probabilidade.

\section{RESULTADOS E DISCUSSÃO}

Avaliando a resistência do recobrimento através da simulação do transporte e plantio manual das sementes, observa-se que as proporções 0,5 e $1 \%$ de cimentante tiveram perdas estatisticamente superiores às proporções 2, 3, 4 e 5\% (Figura 1).

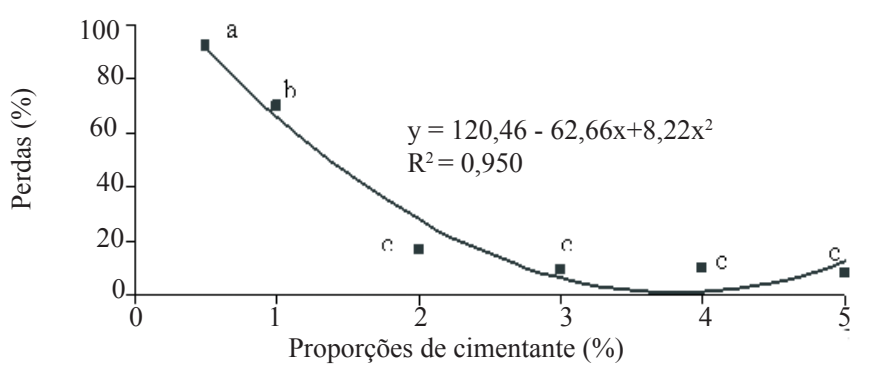

FIGURA 1. Perda do material de recobrimento em função da proporção de cimentante utilizado no recobrimento de sementes de milho após simulação de transporte e semeadura manual. $C V=13,34 \%$.

Médias seguidas pelas mesmas letras não diferem entre si pelo teste de Tukey a 5\% de probabilidade.

As proporções 2, 3, 4 e 5\% de cimentante foram estatisticamente iguais, entretanto a proporção de $2 \%$ seria 
recomendada. A utilização da menor proporção de cimentante, desde que não comprometa a resistência do recobrimento, é mais vantajosa economicamente, além disso, quanto menor a proporção de cimentante menor a dificuldade de absorção de água e oxigênio.

Utilizando menor quantidade de cimentante, se tem ao reidratar as sementes recobertas após a semeadura, uma solução com menor viscosidade na camada do recobrimento, $\mathrm{o}$ que facilita a drenagem da água retida nos poros, favorecendo assim, a sua desobstrução e, conseqüentemente, a troca gasosa. Isto ocorre porque os cimentantes são, geralmente, produtos espessos e a viscosidade da solução depende da sua concentração como afirmam Silva e Nakagawa (1998b).

Nas avaliações de perda do material de recobrimento utilizando semeadura mecânica, as proporções de 4 e $5 \%$ de cimentante tiveram perdas estatisticamente inferiores às proporções 0,$5 ; 1 ; 2$ e 3\% (Figura 2).

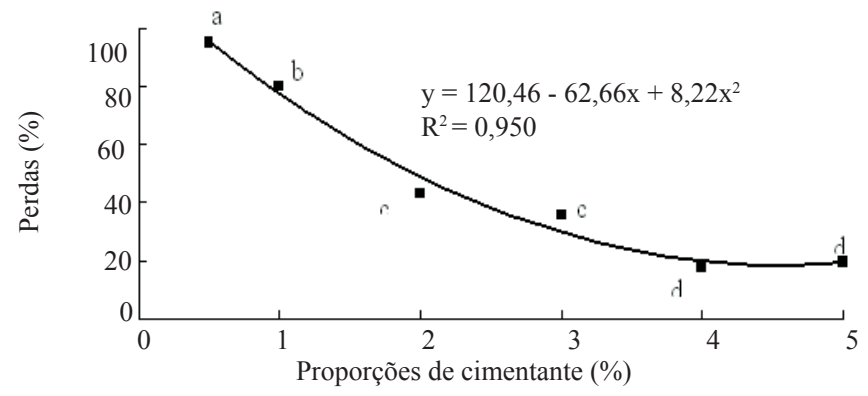

Médias seguidas pelas mesmas letras não diferem entre si pelo teste de Tukey a $5 \%$ de probabilidade.

FIGURA2. Perda do material de recobrimento em função da proporção de cimentante utilizado no recobrimento de sementes de milho após passarem pela semeadora. $\mathrm{CV}=\mathbf{1 2 , 0 1 \%}$.

Esses resultados estão de acordo com Silva e Nakagawa (1998b), segundo os quais, a firmeza da ligação entre as partículas define a consistência do recobrimento e, quanto maior a proporção do cimentante, maior é a ação de fixação das estruturas.

Os dados mostram que há necessidade de maior proporção de cimentante no recobrimento das sementes que passam pela semeadora em relação à semeadura manual. Isto acontece porque as sementes que passam pela semeadora sofrem maior atrito mecânico, necessitando de maior proporção de cimentante para que o recobrimento não desmanche durante o processo, recomendando então 4\% de cimentante.

A proporção de plântulas normais obtidas no teste de germinação e teste frio sem solo não foi afetada pelas proporções de cimentante avaliadas (Tabela 1).
TABELA 1. Porcentagem de plântulas normais do teste de germinação e teste frio sem solo de sementes de milho UENF 506-8 recobertas com diferentes proporções de cimentante.

\begin{tabular}{lcc}
\hline Tratamentos & Germinação (\%) & Teste Frio (\%) \\
\hline Sementes nuas & $95 \mathrm{a}$ & $86 \mathrm{a}$ \\
$0,5 \%$ de cimentante & $91 \mathrm{a}$ & $91 \mathrm{a}$ \\
$1 \%$ de cimentante & $91 \mathrm{a}$ & $91 \mathrm{a}$ \\
$2 \%$ de cimentante & $91 \mathrm{a}$ & $94 \mathrm{a}$ \\
$3 \%$ de cimentante & $91 \mathrm{a}$ & $94 \mathrm{a}$ \\
$4 \%$ de cimentante & $88 \mathrm{a}$ & $91 \mathrm{a}$ \\
$5 \%$ de cimentante & $90 \mathrm{a}$ & $85 \mathrm{a}$ \\
\hline \multicolumn{1}{c}{ CV\% } & 7,22 & 6,97 \\
\hline
\end{tabular}

As médias dentro de cada coluna seguidas da mesma letra não diferem entre si pelo teste de Tukey, a 5\% de probabilidade.

Esses resultados corroboram com Silva et al. (2002), os quais observaram que diversas composições de cimentantes utilizadas no recobrimento não afetaram a proporção de germinação de sementes de alface recobertas.

Nas avaliações da primeira contagem do TG e IVE, FIGURA 3, é possível observar redução na velocidade de germinação (primeira contagem do TG) e no IVE, quando a proporção de cimentante aumentou de 2 para $3 \%$. Isto pode estar relacionado com a maior dificuldade de absorção de água e oxigênio ocasionada pelo aumento da proporção de cimentante.

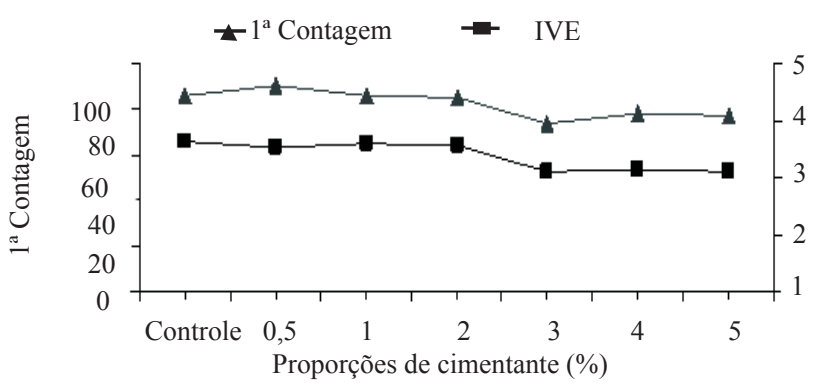

FIGURA 3. Primeira Contagem do TG e índice de Velocidade de Emergência (IVE) de sementes de milho UENF-506-8 recobertas com diferentes proporções de cimentante. $\mathrm{CV}=\mathbf{1 0 , 3 1 \%}$ e $10,11 \%$.( respectivamente).

Comparando os resultados obtidos no teste de germinação (Tabela 1) e na emergência em casa de vegetação (Figura 4), observa-se que o aumento na proporção de cimentante não afetou o número de plântulas normais no teste de germinação, mas na avaliação de emergência em casa de vegetação 
houve pequena redução, quando a proporção de cimentante aumentou de 2 para $3 \%$. Isso pode estar relacionado com a maior disponibilidade de água e temperatura ideal na câmara de germinação, garantindo a eficiência do processo de germinação, enquanto a areia retém pouca umidade, e com isso dificulta a absorção de água pelas sementes com maior proporção de cimentante, diminuindo o número de plantas emergidas.

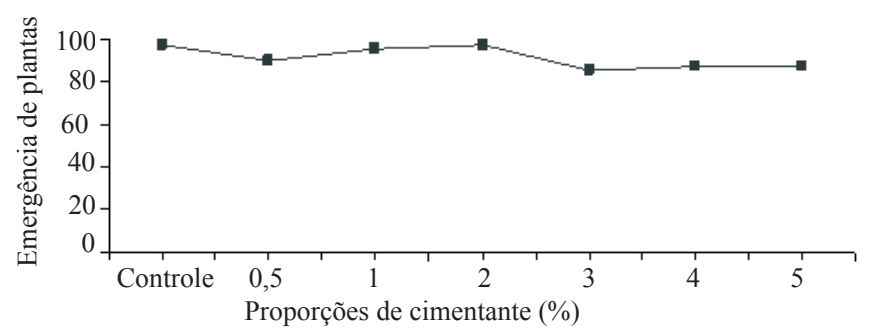

FIGURA 4. Emergência de plantas em casa de vegetação de sementes de milho UENF-506-8 recobertas com diferentes proporções de cimentante. $\mathrm{CV}=10,94 \%$.

Esses resultados estão de acordo com Pires et al. (2004), Oliveira et al. (2003), Pereira e Oliveira (2003) e Silva et al. (2002), os quais também verificaram que a porcentagem de germinação não foi reduzida pelo recobrimento, apesar da velocidade de germinação das sementes ter sido afetada devido à presença de uma barreira física.

Segundo Costa et al. (2001), as sementes recobertas demoram mais tempo para absorver a umidade do solo, podendo tardar a germinação em até 48 horas a mais que as sementes nuas.

Entre as proporções de cimentante avaliadas para a semeadura manual, $2 \%$ é a proporção recomendada, visto que entre as proporções testadas, esta apresentou alta resistência e não afetou a qualidade fisiológica das sementes.

Para semeadura mecânica, recomenda-se a proporção de $4 \%$ de cimentante, pois esta proporção promove ao recobrimento boa resistência e possivelmente, em áreas de produção com chuvas regulares ou com um sistema eficiente de irrigação onde não haja limitação de umidade, esta proporção de cimentante não afete a emergência das plantas.

\section{CONCLUSÕES}

O recobrimento, nas diversas proporções de cimentante testadas, não afetou significativamente a qualidade fisiológica das sementes de milho UENF 506-8.

Para a semeadura manual, das sementes de milho UENF 506-8, recomenda-se a utilização de $2 \%$ de cimentante e para a semeadura mecanizada $4 \%$ de cimentante.

\section{REFERÊNCIAS}

BALDANI, V.L; BALDANI, J.I.; OLIVARES, F.L.; DÖBEREINER, J. Identification and ecology of Herbaspirillum seropedicae and the closely related Pseudomonas rubrisubalbicans. Symbiosis, v.13, p. 65-73, 1992.

BAYS, R.; BAUDET, L.; HENNING, A.A.; LUCCA FILHO, O. Recobrimento de sementes de soja com micronutrientes, fungicida e polímero. Revista Brasileira de Sementes, Brasília, v.29, n.2, p. 60-67, 2007.

BINNECK, E.; BARROS, A.C.S.A.; VAHL, L.C. Peletização e aplicação de molibdênio em sementes de trevo-branco. Revista Brasileira de Sementes, Brasília, v.21, n.2, p. 203207, 1999.

BRASIL Ministério da Agricultura e Reforma Agrária. Regras para análise de sementes. Brasília: SNDA/DNDV/ CLAV, 1992. 365 p.

COSTA, C.E.L.; SILVA, R.F.; LIMA, J.O.G.; ARAÚJO, E.F. Sementes de cenoura, Daucus carota L., revestidas e peliculadas: germinação e vigor durante o armazenamento. Revista Brasileira de Armazenamento, Viçosa, v. 26, p. 36-45. 2001.

FRANZIN, S.M.; MENEZES, N.L.; GARCIA, D.C.; ROVERS, T. Avaliação do vigor de sementes de alface nuas e peletizadas. Revista Brasileira de Sementes, Pelotas, v. 26, n. 2, p. 114-118, 2004.

GIMÉNEZ-SAMPAIO, T.; SAMPAIO, N.V. Recobrimento de sementes. Informativo ABRATES, Londrina, v. 4, n. 3, 1994, $52 \mathrm{p}$.

MAGUIRE, J.D. Speed of germination aid in seletion and evaluation for emergence and vigour. Crop Science, Madison, v.2, n. 2, p. 176-177, 1962.

MEDEIROS, E.M.; BAUDET, L.; PERES, W.B.; EICHOLZ, E.D. Modificações na condição física das sementes de cenoura em equipamento de recobrimento. Revista Brasileira de Sementes, Pelotas, v. 26, n. 2, p.70-75, 2004.

MENDONÇA, E.A.F. Revestimento de sementes de milho superdoce. 2003. 63 f. Tese (Doutorado em Agronomia) Faculdade de Ciências Agrárias e Veterinárias do campus de Jaboticabal - UNESP, Jaboticabal - SP, 2003. 
NASCIMENTO, W.; SILVA, J.; MARTON, L. Qualidade fisiológica de sementes peletizadas de tomate durante o armazenamento. Informativo ABRATES. Londrina, v.3, n.3, p.47, 1993.

OLIVEIRA, J.A.; PEREIRA, C.E.; GUIMARÃES, R.M.; VIEIRA, A.R.; SILVA, J.B.C. Desempenho de sementes de pimentão revestidas com diferentes materiais. Revista Brasileira de Sementes, Pelotas, v.25, n. 2, p. 36-47, 2003.

PEREIRA, C.E.; OLIVEIRA, J.A. Qualidade Fisiológica e Sanitária de sementes de Brachiaria decumbens revestidas e tratadas com inseticida e fungicida. Informativo Abrates, Londrina, v. 13, n. 3, p. 227 (resumo 331), 2003.

PIRES， L.L.; BRAGANTINI， C.; COSTA， J.L.S. Armazenamento de sementes de feijão revestidas com polímeros e tratadas com fungicidas. Pesquisa Agropecuária Brasileira, Brasília, v. 39, n. 7, p. 709-715, 2004.
SILVA, J.B.C.; NAKAGAWA, J. Metodologia para avaliação de materiais cimentantes para peletização de sementes. Horticultura Brasileira, Brasília, v. 16, n. 1, p. 31-37, 1998a.

SILVA, J.B.C.; NAKAGAWA, J. Metodologia para avaliação de materiais cimentantes para peletização de sementes. Horticultura Brasileira, Brasília, v.16, n.1, p. 31-37, 1998b.

SILVA, J.B.C.; SANTOS, P.E.C; NASCIMENTO, W.M. Desempenho de sementes peletizadas de alface em função do material cimentante e da temperatura de secagem dos péletes. Horticultura Brasileira, Brasília, v. 20, n. 1, p. 6770,2002 